\title{
ЗНАЧЕНИЕ ФРЕЙМОВОГО ПОДХОДА В ФОРМИРОВАНИИ МЕТАФОР В СТРОИТЕЛЬНОМ ДИСКУРСЕ
}

\section{THE IMPORTANCE OF FRAME APPROACH IN FORMATION OF METAPHORS IN THE BUILDING DISCOURSE}

M. Yurina

Summary: In this article the data on the frame, metaphor and discourse, presented in linguistic works, have been analyzed and summarized to identify the significance of using the frame approach in the process of metaphorization in the building discourse. The language material was provided by texts of popular science building and scientific and technical magazines and newspapers. In the article the main methods are used such as observation and generalization, frame analysis and extrapolation. The results of the study are to identify the importance of using the frame approach as a structural organizational and informational mechanism in the formation of building metaphors.

Keywords: frame approach, building discourse, metaphor, frame, terminology.
A ктуальность темы исследования, которой посвящается предлагаемая статья, определяется несколькими аспектами. Когнитивная лингвистика, зародившаяся в середине XX века и составляющая один из разделов лингвистики, где объектом исследования является язык как «механизм познания», продолжает исследования ментальных структур, фиксирующих и хранящих информацию о мире и опыте человека. Ментальные структуры разделяют на неделимые когнитивные единицы знаний, представленные в виде концептов, и на сложные когнитивные единицы - фреймы, сценарии, схемы и т.д. Однако ученые не перестают проявлять пристальный интерес к дальнейшему изучению и пониманию не только концептов, но фреймов и их составляющих. Известно, что фрейм является междисциплинарным феноменом, а понятие фрейма в лингвистике рассматривают, с одной стороны, как структуру знания, с другой стороны, как структуру представления знания. Анализируя тезаурус любого дискурса, а именно его лексический состав, фрейм, обладающий той или иной информацией, соответствующей определенной языковой сфере, определяют в качестве структуры представления знания или систематизированной базы данных, репрезентирующий какой-либо концептуальный объект или интерпретированную форму концепта. Одна из интерпретированных форм концепта - это метафора, которая является одним из основных источников, образующих тезаурус или терминосистему профессионального дискурса, притом компоненты структурированных

\author{
Юрина Мария Константиновна \\ аспирант, Московский государственный \\ областной университет \\ rose2013@inbox.ru
}

Аннотация: В статье производится изучение и обобщение данных о фрейме, метафоре и дискурсе, представленных в лингвистических трудах, с целью выявления значимости применения фреймового подхода в процессе метафоризации в строительном дискурсе. Языковым материалом послужили тексты строительных научно-популярных и научно-технических журналов и газет. В статье были использованы такие методы, как наблюдение и обобщение, фреймовый анализ и экстраполяция. В результате исследования доказана важность использования фреймового подхода как структурного организационно-информационного механизма в формировании строительных метафор.

Ключевые слова: фреймовый подход, строительный дискурс, метафора, фрейм, терминология.

представлений, знания, формирующие метафору, обеспечивает фрейм и его составляющие. Помимо всего прочего, актуальность применения фреймового подхода как инструмента структурирования и репрезентации конкретной области опыта и знаний к дискурсу заключается в том, что в социуме постоянно происходит развитие различных сфер жизнедеятельности человека, а это значит постоянное обновление и дополнение тезауруса профессионального дискурса. И такому же значительному пополнению новыми лексемами подвергается терминосистема строительного дискурса, которая, в свою очередь, как и другие профессиональные дискурсы, стремится к созданию своих терминов путем использования процесса метафоризации. В настоящей статье рассматривается роль фреймового подхода в организации и формировании метафор различного типа в строительном дискурсе с опорой на существующие научные источники по данной проблематике, а также анализ тезауруса строительного дискурса для выявления видов и количества метафор, проведенный на основе изучения текстов из научно-популярных и научно-технических журналов по строительной тематике.

Для достижения указанной цели исследования необходимо решить следующие задачи: во-первых, проанализировать сведения о фрейме, метафоре и строительном дискурсе; во-вторых, выявить взаимосвязь между фреймом и метафорой в строительном дискурсе; в-третьих, обосновать важность фреймового подхода в 
образовании метафоры в строительном дискурсе.

Для понимания роли фреймового подхода и анализа значений фрейма, метафоры и строительного дискурса в статье применяются следующие методы исследования: наблюдение и обобщение, фреймовый анализ и экстраполяция.

Теоретической базой исследования, наряду с научными трудами Н.Д. Арутюновой, А.П. Бабушкина, А.П. Болдырева, В.Н. Телия, М. Минского и т.д., послужили работы российских и зарубежных лингвистов Э.В. Будаева, А.П. Чудинова, Д. Лакоффа, М. Джонсона, Ж. Фоконье, М.Тернера и многих других для установления и демонстрации сути номинативной, концептуальной и художественной метафоры и влияния фреймового подхода на их наличие в строительном дискурсе.

Исследование проблем терминологии различных видов профессионального дискурса постоянно вызывает научный интерес, что можно объяснить социальными, практическими и лингвистическими причинами. Одной из целей профессиональной коммуникации может быть описание и толкование того или иного явления, относящегося к определённой профессиональной деятельности, во время такого общения коммуниканты используют слова и выражения тематической направленности, соответствующие определённым грамматическим и семантическим правилам. Такие слова и выражения являются терминами, и они же создают профессиональный контекст коммуникативной ситуации, а именно формируют профессиональный дискурс.

Главным принципом лексико-семантического формирования терминосистемы профессионального дискурса является процесс метафоризации путем увеличения смыслового объёма лексемы за счёт образования у неё переносных значений. Известно, что метафору в лингвистике делят на следующие виды: абсолютная метафора (метафорическая метафора как результат научного открытия); визуальная метафора («слияние двух различных областей опыта, образующих новые смысловые поля» [15; с. 195]); лексическая метафора (совокупность лексем, где «первоначальный метафорический перенос уже не воспринимается» [12]); развернутая метафора (метафора «распространена на протяжении большого фрагмента текста при помощи детализации» [13; с. 48]); когнитивная (концептуальная) метафора (метафора, в которой одна идея (или концептуальная область) реализуется в терминах другой); номинативная метафора (данный тип метафоры «образуется за счёт сходства: признака, формы, состояния, функций предметов, звучаний») [2; с. 8]; художественная метафора (такая метафора обладает своей уникальностью и «двуплановостью значения, которая обеспечивает образноэстетическую функцию» [17; с. 164]); языковая метафора (отражает «коллективные предметно-логические связи, выполняет коммуникативную функцию» [18; с. 34], воспроизводится спонтанно в речевой деятельности, свободна от субъективной точки зрения, индивидуальности и неповторимости).

Как правило, именно «благодаря номинативной метафоре человечество имеет возможность» [1; с. 191] создавать новые термины, поскольку обладает особенностями переноса названия с одного объекта или явления на другой «с изменением значения» [3, с. 40]. Однако наряду с номинативной метафорой при исследовании устных и письменных источников профессиональных дискурсов обнаруживается частое использование художественной и концептуальной метафоры. Терминосистема строительного дискурса не стала исключением. Строительная отрасль динамично развивается благодаря экономической и технологической международной интеграции, что оказывает влияние на значительное расширение лексического состава терминосистемы строительного дискурса. При анализе текстов строительных научно-популярных и научно-технических журналов и газет методом сплошной выборки, анализа словарных дефиниций, наблюдения и обобщения для лучшего понимания и определения функциональных особенностей метафоры в строительном дискурсе было выявлено наличие:

- номинативный метафоры в качестве элемента, обогащающего новыми лексемами терминосистему строительного дискурса: капилляры стен, подошва фундамента, волосяная кисть, цементное молоко, водосборная воронка, минеральная вата, мелкозернистый бетон, жила горячего и холодного водоснабжения, лицевая кладка, сердцевина троса, пирог утеплителя в кровле, индивидуальный кожух для утеплителя, зелёный позвоночник, дома-обёртки, бетонное полотно и т.д.;

- концептуальной метафоры, которая формируется путем соединения образов, ассоциаций и опыта, извлечённых из взаимосвязи человека и окружающей его среды: модульный дом - музыкальное произведение, бетонная конструкция - тело, фасад - «лицо» здания или жилища, инженерные системы - внутренние органы (города);

- художественной метафоры, выражающей авторскую индивидуальность и обладающую особенностями антропоморфизма: железобетонная стяжка поверх одно- или двухслойной теплоизоляции ликвидирует проблему, нижние слои теплоизоляции страхуют, нижние и верхние кровельные плиты дополняют свойства друг друга, гидроизоляционные мембраны завершают покрытия, эксплуатируемые поверхности испытывают механические нагрузки.

Когнитивный характер процесса метафоризации, заключающийся в способности к познанию, организации, оценки и представлений окружающих объектов дей- 
ствительности, дает бесспорное преимущество метафоре, соединяющей в себе образы, ассоциации, шаблоны, определяющие разные категории явлений, созданные благодаря накопленным знаниям человека о мире, является эффективным приёмом образования новых понятий в строительном дискурсе. Возведение зданий, строений, конструкций, сооружений, происходящее путём использования тех или иных материалов и элементов, руководствуясь инженерными изысканиями, можно объяснить или описать, употребляя лексику, входящую в состав любого другого дискурса, которая при помощи процесса метафоризации формируется в номинативную, концептуальную или художественную метафору в зависимости от представления объекта познания согласно вышеуказанному полученному результату о наличии различных видах метафоры в строительном дискурсе. Например, в строительном дискурсе номинативная метафора «минеральная вата» отписывает волокнистый материал, получаемый из расплавов горных пород или металлургических шлаков и их смесей. Данный термин, созданный процессом метафоризации и впоследствии рассматриваемый как номинативная метафора, имеет в своём лексическом составе понятие «вата», взятое из терминологии медицинского дискурса для номинации представленного материала, с учетом схожих свойств и назначения: «пушистая масса волокон» или "волокнистый материал, иногда с примесью синтетических волокон, слабо переплетённых между собой в различных направлениях». Ввиду того, что процесс метафоризации располагает информационно-смысловым блоком, где содержатся образы и ассоциации познавательного характера, метафора представляет собой разновидность концепта. Рассматривая метафору как явление когнитивного порядка, следует обратить внимание, что данный феномен определяется тремя составляющими - концептом, фреймами и слотами.

В настоящее время не существует однозначного понимания термина концепт, так как данное явление охватывает сразу когнитивистику, семантику и лингвокультурологию. Известно, что родоначальником понятия концепт стал лингвист С.А. Аскольдов. Данное явление было впервые упомянуто в статье «Концепт и слово», написанной С.А. Аскольдовым, где он охарактеризовал концепт, как «мысленное образование, которое знаменует нам в процессе мысли неопределённое множество предметов одного и того же рода» [4, с. 269]. Конечно, следует отметить иные точки зрения на то, что же является концептом:

- З.Д. Попова и И.А. Стернин описывают концепт как «дискретное ментальное образование» [14, c. 24], являющееся основным элементом мышления человека, который характеризуется чёткой внутренней организацией информационной составляющей о том или ином объекте или явлении, опираясь на общее восприятие или понимание того или иного объекта или явления;
- А.П. Бабушкин определяет концепт как любой отдельный ёмкий элемент общественного восприятия, изображающий объект действительности, «хранимый в национальной памяти носителей языка в виде познанного субстрата» [5, с. 29];

- В.Н. Телия отмечает, что «концепт - это всегда знание, структурированное во фрейм» $[16$, с. 96];

- В.В. Колесов рассматривает концепт в качестве «семантического «зародыша» слова» [10, с. 50];

- В.И. Карасик отмечает, что концепт владеет понятийной, образной и ценностной составляющей [9; с. 91].

Согласно вышеперечисленным определениям, можно сделать вывод, что данное явление - это, в первую очередь, «мыслительные образы, стоящие за языковыми знаками, означаемые языковых знаков» $[11$, с. 6]. Мыслительные образы являются репрезентацией ментального мира людей, и эти образы могут делиться по характеру знаний: схемы, прототипы, фреймы, стереотипы, сценарии и даже метафоры, поскольку при помощи метафоры возможно актуализировать скрытые мыслительные функции для отражения субъективного понимания определенного объекта действительности, применяя разнообразные понятийные концепции для формирования нового понятия или образа в нашем мышлении.

Что касается такого явления как фрейм, то впервые понятие фрейма ввёл М. Минский в 1975 г., определив его как «единицу представления знаний» [19, с. 4]. Наряду с представленным М. Минским определением фрейма возникло когнитивное, психологическое и социологическое восприятие данного явления. В российской лингвистической традиции образовались два подхода к пониманию и изучению фрейма - лингвокогнитивный и лингвокультурный. С позиции лингвокогнитивного подхода фрейм рассматривают как модель или составляющую концепта, а с точки зрения лингвокультурного подхода - как субстрат концепта. Следует отметить, что концепт и фрейм тесно связаны между собой. Фрейм может выступать в качестве «объёмного, многокомпонентного концепта» [8, с. 25], обладающего обширной информацией и знаниями о ситуации или об объекте действительности. Иначе говоря, концепт описывает ряд однородных реалий действительности, в то время как фрейм заключает в себе конкретные знания с определенным набором ситуаций и понятий, хранящий не только очевидные, но и скрытые сведения. Таким образом, фрейм является некой структурой данных для отражения или определения объекта действительности. Информация, относящаяся к фрейму, содержится в слотах, которые являются базовым структурным элементом. Слоты обозначают незаполненные подструктуры фрейма. После заполнения этих подструктур значимыми сведениями, фрейм представляет ту или иную ситуацию или реалии действительности. 
Следовательно, метафора представляет интерпретированную форму концепта на основании сходства понятий явлений, фреймы являются набором тех или иных образов, олицетворяющих реалии действительности, а слоты подчеркивают информативную сторону фрейма. Следует отметить, что фрейм не только соединяет в себе понятия и представления, которые являются фундаментом формирования метафоры, но и структурирует эти знания в процессе метафоризации, объединяя множество фреймов, состоящих из компактных знаний о типовых ситуациях или реалиях действительности посредством активации алгоритмического и дискурсивного глубинного мыслительного процесса. На основе вышесказанного рассмотрим одну из строительных номинативных метафор «капилляры стен». Как правило, в представлении любого человека возникает следующее определение понятия «капилляры» - тончайшие кровеносные сосуды. Однако благодаря процессу метафоризации произошёл перенос значения данной лексемы из медицинской лексики при трансформации собственного значения в другой дискурс согласно имеющимся общим признакам у данных реалий. В строительном дискурсе термин «капилляры», представленный в качестве строительной номинативной метафоры определяет систему сообщающихся мелких пор и очень узких каналов. Надо отметить, что в основе образования строительной номинативной метафоры «капилляры стен» лежит фреймовый подход, обеспечивающий не только в данном примере процесс метафоризации, но и в целом, правильной организацией знаний, так как именно фрейм предполагает структурированную или систематизированную базовую информацию, отражающую все свойства анализируемого объекта или явления действительности. Получается, что процесс метафоризации требует применения фреймового подхода, потому что сама метафора, в независимости от вида, состоит из множества фреймовых систем и фреймов, где записана соответствующая информация о реалиях действительности. Учитывая, что в строительных текстах и в самом строительном дискурсе есть не только частые случаи употребления и наличия строительной номинативной метафоры, но и строительной концептуальной метафоры, создание которой непосредственно предполагает применение фреймового подхода также. Например, анализируя строительную концептуальную метафору «Bonolit D300 (газобетон) - атмосфера чистого комфорта» [7; с. 30], которая представлена в качестве заголовка статьи строительного журнала «Технологии строительства», было установлено наличие применения фреймового подхода, поскольку сфера-мишень состоит из фреймов, разделенных на группы по следующим ассоциативным качествам - прочность, энергоэффективность, экологичность, морозостойкость, огнестойкость, эксплуатационная безопасность, экономичность и инвестиционная привлекательность, то совокупность таких схем образов, образующих организованную систему фреймов и составляющую сферу-мишень, является прецедентом для создания сферы-мишени посредством метафорического переноса и приобретения вторичного значения за счёт характеристики схем образов системы фреймов, выражаясь в значении «уютного жизненного пространства» или «атмосфера чистого комфорта». Такой алгоритм действия, предполагающий в данном случае образования строительной концептуальной метафоры, лежит в основе фреймового подхода. Что касается строительных художественных метафор, которые могут встречаться в строительном дискурсе, то проявление их уникальности, авторства и эстетических функций олицетворения рождается благодаря фреймовому подходу: информационно-смысловой блок схем образов, представленных в фреймах, а впоследствии фреймовых системах, является совокупностью накопленных знаний о реалиях действительности, предопределяющей формирование метафоры. К примеру, при изучении предложения «Физические свойства компонентов предварительно изолированных труб в гофрированном кожухе позволяют достичь высоких показателей сбережения тепловой энергии при прокладке тепловых сетей, защитить трубы от промерзания при отрицательной температуре и увеличить срок эксплуатации в связи с уменьшением агрессивного воздействия окружающей среды» [6; с. 92] была обнаружена строительная художественная метафора «физические свойства позволяют достичь, защитить, увеличить». Конечно, данная метафора выполняет образную эстетическую задачу олицетворения, но для появления данной художественной метафоры понадобились схемы образы, образующие фреймы, такие, как описание технологичных процессов и современные методы и способы создания трубопроводов, характеризующие физические свойства компонентов, при этом, комплекс таких схем образов, в свою очередь, формируют при систематизации данных знаний в себе уникальную художественную метафору. Это еще раз доказывает, что применение фреймового подхода способствует образованию новых метафор в строительном дискурсе.

Таким образом, изучив теоретические данные о фрейме, метафоре и лингвистической составляющей строительного дискурса, мы приходим к следующим выводам: любой тип метафоры образуется при помощи процесса метафоризации, который предполагает семантическое развитие тезауруса или терминосистемы дискурса, а также фреймовый подход, поскольку исключительно фреймовая система и фреймы, содержащие конкретные знания о реалиях действительности, позволяют гарантировать упорядочение этих знаний согласно свойствам анализируемого объекта или предмета, обращаясь к дискурсивному мышлению. Фреймовый подход является основным условием образования любого вида метафоры, которая, в свою очередь, пополняет терминологическую систему новыми лексемами и знаниями, так как метафоризация как процесс чрезвычайно активна при создании новых терминов и знаний, что реализуется, в том числе, и в строительном дискурсе. 


\section{ЛИТЕРАТУРА}

1. Антропова Е.К., Зимовец Н.В. Метафора языковая и речевая // Наука и образование: отечественный и зарубежный опыт / Сборник статей двадцать пятой международной научно-практической конференции, Белгород, 25 ноября 2019 г. Белгород: Изд-во «000 ГиК», 2019. С. 190-194.

2. Ахмад А.О., Березуцкая Д.О. Особенности процесса номинации. Номинативная метафора и метонимия в аспекте англоязычного рекламного текста // Актуальные проблемы гуманитарных и естественных наук. М.: Научно-информационный издательский центр и редакция журнала «Актуальные проблемы гуманитарных и естественных наук», 2017. С. 7-9.

3. Аристотель. Поэтика. Риторика / пер. с др.-греч. В. Аппельрота, Н. Платоновой. СПб.: Азбука, Азбука-Аттикус, 2018. 320 с.

4. Аскольдов С.А. Концепт и слово // Русская словесность. От теории словесности к структуре текста: антология / под общ. ред. В.П. Нерознака. М.: Academia, 1997. C. 269-279.

5. Бабушкин А.П. Типы концептов в лексико-фразеологической семантике языка. Воронеж: Изд-во ВГУ, 1996. 104 с.

6. Банников Д., Дюпина Н., Жеребцов А. Высокоэффективные трубопроводы водоснабжения и теплоснабжения // Технология строительства. М.: 000 «Вива-Стар», 2018. № 2(124). С. 92-93.

7. Банников Д., Дюпина Н., Жеребцов A. Bonolit D300 - атмосфера чистого комфорта! Энергоэффективность В «300-ой степени»! // Технология строительства. М.: 000 «Вива-Стар», 2018. № 2(124). С. 30-31.

8. Болдырев Н.Н. Концепт и значение слова // Методологические проблемы когнитивной лингвистики / под ред. И. А. Стернина. Воронеж: Воронеж. гос. ун-т, 2001. С. 25-36.

9. Карасик В.И. Языковой круг: личность, концепты, дискурс. М.: Гнозис, 2004. 390 с.

10. Колесов В.В. Философия русского слова. СПб.: Изд-во «Юна», 2002. С. 50 - 51.

11. Никишина И.Ю. Понятие «концепт» В когнитивной лингвистике // Язык, сознание, коммуникация: Сб. статей. М.: Макс Пресс, 2002. Вып.21. С. 6 - 7.

12. Розенталь Д.Э. Словарь-справочник лингвистических терминов. М.: Просвещение, 1985.400 c. URL: https://www.gumer.info/bibliotek_Buks/Linguist/ DicTermin/p_1.php (дата обращения: 21.01.2021)

13. Панкратова С.А. Развернутая метафора в манипулятивном дискурсе // Актуальные проблемы филологии и лингвистики. Владикавказ: ФГБОУ В0 «Северо-Осетинский государственный университет им. К.Л. Хетагурова», 2018. № 3(31). С. 48-53.

14. Попова 3.Д., Стернин И.А. Семантико-когнитивный анализ. Воронеж: Изд-во «Истоки», 2006. 250 с.

15. Попова 0.В. Метафора как когнитивное средство создания визуальной образности // Научные ведомости БелГУ. Серия Гуманитарные науки. Белгород: Изд-во БелГУ, 2017. № 7(256). Вып. 33. С. 194-198.

16. Телия В.Н. Русская фразеология. Семантический, прагматический и лингвокультурологические аспекты. М.: Школа «Языки русской культуры», 1996.288 с.

17. Шаваева Ф.Я. Языковая художественная метафора. Специфика функционирования метафоры в художественном тексте // Филологические науки. Вопросы теории и практики. Тамбов: Грамота, 2016. № 5(59): в 3-х ч. Ч. 1. С. 164-167.

18. Popova T.G. Metaphor in Cross-Culture // The 19th International Conference of the International Association for Intercultural Communication Studies (IAICS) and Far Eastern Federal University «Exploring Diversity to Reach Understanding Across Culture», Vladivostok, October 3-5, 2013. Vladivostok: Far Eastern Federal University, 2013. pp. 34-38.

19. Minsky M. A framework for representing knowledge. The Psychology of Computer Vision (ed. P.H. Winston). New York: McGraw-Hill, 1975. pp. 211-277.

( Юрина Мария Константиновна (rose2013@inbox.ru). 